\title{
Neurological signs and imaging findings in three cats with multiple articular process hypertrophy
}

\author{
Neurologische symptomen en resultaten van medische beeldvorming bij \\ drie katten met hypertrofie van multipele articulaire processen
}

${ }^{1}$ D. Polidoro, ${ }^{1}$ I. Cornelis, ${ }^{2}$ T. Rick, ${ }^{1}$ L. Van Ham, ${ }^{1}$ N. Burger, ${ }^{1}$ N. Devriendt, ${ }^{1}$ T. Roggeman, ${ }^{1}$ S.F.M. Bhatti

${ }^{1}$ Small Animal Department, Faculty of Veterinary Medicine, Ghent University, Salisburylaan 133, 9820 Merelbeke, Belgium

${ }^{2}$ Department of Veterinary Medical Imaging and Small Animal Orthopedics, Faculty of Veterinary Medicine, Ghent University, Salisburylaan 133, 9820 Merelbeke, Belgium

dakir.polidoro@ugent.be

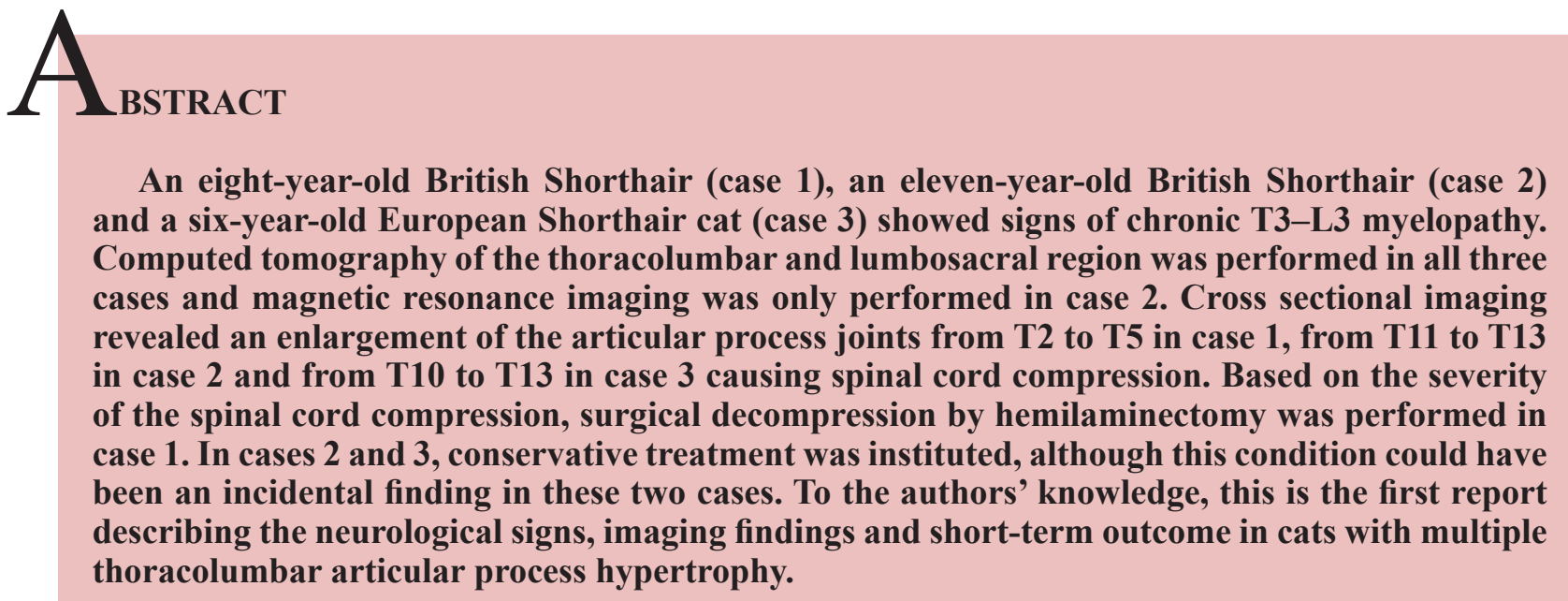

\section{SAMENVATTING}

Een acht jaar oude Britse korthaar (casus 1), een elf jaar oude Britse korthaar (casus 2) en een zes jaar oude Europese korthaar (casus 3) werden aangeboden met chronisch progressieve T3-L3 myelopathie. Computertomografie van de thoracolumbale en lumbosacrale wervelkolom werd uitgevoerd bij deze drie casussen en magnetische resonantiebeeldvorming werd gedaan bij casus 2 . Op deze beeldvorming werd hypertrofie van de gewrichten van de articulaire processen gezien van T2 tot T5 in casus 1, van T11-T13 in casus 2 en van T10 tot T13 in casus 3; met compressie van het ruggenmerg. Wegens de ernst van de ruggenmergcompressie werd een chirurgische decompressie uitgevoerd bij casus 1 . Bij de andere twee gevallen werd een conservatieve behandeling ingesteld, alhoewel deze aandoening in deze gevallen een toevalsbevinding zou kunnen zijn. Volgens de auteurs is dit de eerste beschrijving van neurologische symptomen en bevindingen via beeldvorming en van de kortetermijnopvolging bij drie katten met hypertrofie van multipele articulaire processen.

\section{INTRODUCTION}

Articular process hypertrophy (APH) is commonly diagnosed in dogs and its associated signalment, clinical signs and imaging characteristics have been described in the literature (Da Costa, 2010). The clinical signs are mainly related to spinal cord compression, commonly resulting in chronic progressive myelopathy. The main differential diagnosis for APH in cats include angiomatosis (Schur et al., 2010; Hans 

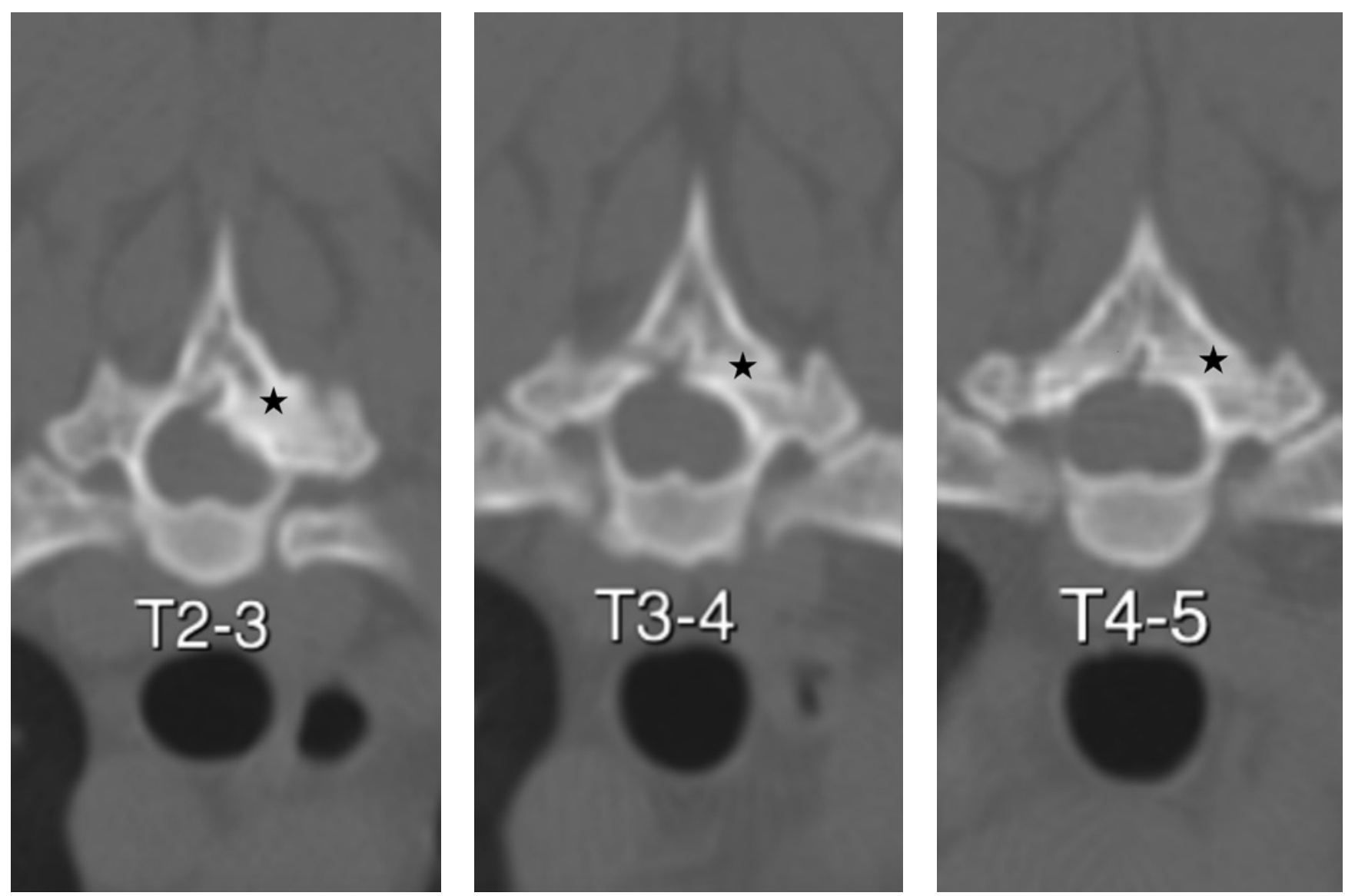

Figure 1. Case 1. Transverse CT bone algorithm acquisition at the level of T2 to T5, showing irregular hypertrophy of the left pedicle (black star) with moderate dorsolateral compression of the spinal cord.

et al., 2018), intervertebral disc disease (De Decker et al., 2017; Crawford et al., 2018), spinal arachnoid diverticulum (Adams et al., 2015), hamartoma (Taylor-Brown et al., 2018), vertebral malformation (Havlicek et al., 2009), spinal dural ossification (Antila et al., 2013), myelomeningocele (Ricci et al., 2011), neoplastic processes (Besalti et al., 2016) and inflammatory or infectious diseases (Marioni-Henry et al., 2004). Information about APH affecting cats, typical imaging characteristics, treatment and outcome is sparse, with only one recent case report about two cats showing single bilateral APH (T11T12 in case 1 and T3-T4 in case 2) (Carletti et al., 2019). Before these two cases, thoracic vertebral canal stenosis due to bilateral APH at the level of T4T5 has been reported in a nine-year-old female intact domestic Shorthair cat (Bossens et al., 2015), but in that particular case, the articular degenerative process was thought to be secondary to adjacent diffuse idiopathic skeletal hyperostosis (DISH). The diagnosis of APH is based on a combination of consistent clinical signs, exclusion of other myelopathies and on characteristic imaging findings. To the authors' knowledge, this is the first report describing the clinical signs and imaging findings in cats with multiple thoracolumbar APH.

\section{CASE DESCRIPTION}

Case 1

An eight-year-old, male, castrated British Shorthair cat was presented with a two-month history of progressive weakness and proprioceptive ataxia in both pelvic limbs, reluctance to jump, and episodes of pain when manipulated by the owners. Administra-

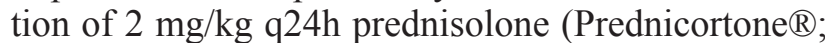
Kela Veterinaria NV, Belgium) by the referring veterinarian for four weeks significantly relieved the neurological signs, but as soon as the medical management was ceased, the clinical signs returned and the cat deteriorated. The cat was referred to the Small Animal Teaching Hospital at Ghent University for further investigations. General physical examination revealed no abnormalities. A complete neurological examination revealed proprioceptive ataxia and ambulatory paraparesis more evident in the left pelvic limb, with absent proprioception and decreased hopping in both pelvic limbs and severe hyperesthesia on palpation of the cranial and mid thoracic vertebral column. Segmental spinal reflexes were normal but moderate to severe muscle atrophy of both pelvic limbs was evident. These findings were consistent with T3-L3 mye- 
lopathy. Complete blood cell count and biochemistry profile were unremarkable. Preanesthetic full cardiac ultrasound was performed, as the cat was an elderly British Shorthair and a mild thickening of the left ventricular free wall and interventricular septum was seen. For this, no treatment was prescribed as these findings were considered to be subclinical.

Computed tomography (CT) (4 slice CT; Lightspeed Qx/i, General Electric Medical Systems, Milwaukee, WI) was performed of the thoracolumbar vertebral column under sedation. The CT images were acquired in bone and soft tissue reconstruction algorithms, with additional IV contrast study. Transverse and reconstructed images in sagittal and dorsal plane were accessed and analyzed using OsiriX DICOM-viewer (Pixmeo, Geneva, Switzerland). Multiple articular process joints along the thoracic and thoracolumbar vertebral column were hypertrophic, causing compression of the spinal cord. At the level of T2 extending to T5, there was an obvious irregular hypertrophy of the left articular process joints with moderate dorsolateral compression of the spinal cord (Figure 1). At the level of T9 extending until the level of T13, there was marked bilateral hypertrophy of the articular processes with moderate to severe dorsal compression of the spinal cord (Figure 2). From T13 until the level of L4, there was mild bilateral hypertrophy of the articular processes with mild dorsal compression of the spinal cord. Based on the CT imaging findings and the marked benign appearance of multiple degenerative processes and the associated spinal cord compression, a presumed diagnosis of multiple degenerative APH was made.

Surgical treatment for spinal cord decompression was performed. A continuous hemilaminectomy was performed along the articular process of T2-T3-T4T5 on the left. Due to their severity and compatibility with a more left sided lesion based on the neurological examination, the cranial thoracic compressions were surgically alleviated first. Inspection of the vertebral canal showed severe dorsolateral deviation of the spinal cord to the right, mainly at the level of T3 (Figure 3). Extra bone was removed dorsally (lamina) at the base of the dorsal spinous processes to achieve extra decompression. Afterwards, an indentation in the spinal cord at the level of the compression remained visible and the spinal cord showed blue discoloration locally. Besides moderate bleeding of the surrounding tissue, no intraoperative complications were noted. A postoperative CT scan revealed satisfactory decompression, especially at the level of T2-T3 (Figure 4). Small fragments of bone from the affected region were submitted for histopathological examination, which revealed mineralized trabecular bone surrounded by osteoblasts with several areas of fibroblast proliferation, consistent with reactive bone tissue. Recovery from anesthesia was uneventful and postsurgical analgesia was provided with $0.2 \mathrm{mg} / \mathrm{kg}$ methadone IV q4h (Insistor ${ }^{\circledR}$; Richter Pharma AG, Austria) $4 \mathrm{mg}$ / $\mathrm{kg}$ carprofen IV q24h (Rimadyl $\AA$; Zoetis Belgium SA, Belgium). Overnight, while hospitalized, the cat started showing episodes of dyspnea, bilateral crackles on lung auscultation, loss of serohemorrhagic fluid from the nose, cyanosis and hypotension, which initially responded to $1-2 \mathrm{mg} / \mathrm{kg}$ boli of furosemide (Dimazon ${ }^{\circledR}$; MSD Santé Animale, France) but worsened within the following hours. A FAST scan of the heart was performed, which showed an increased size of the left atrium. At the owners' request, the cat was euthanized and necropsy was denied.
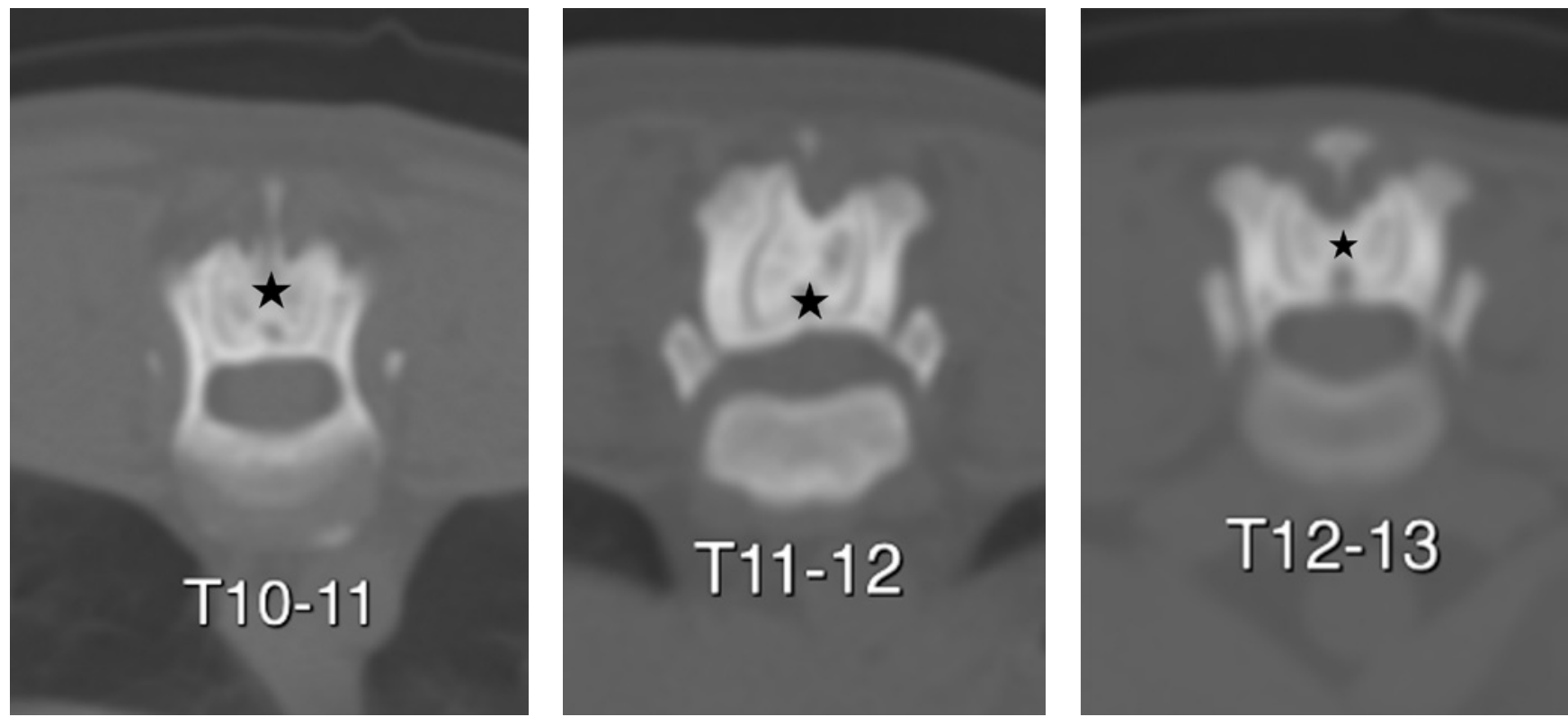

Figure 2. Case 1. Transverse CT bone algorithm acquisition at the level of T10 to T13, showing enlargement and misshaping of the articular process (black star) causing dorsal spinal cord compression bilaterally. 


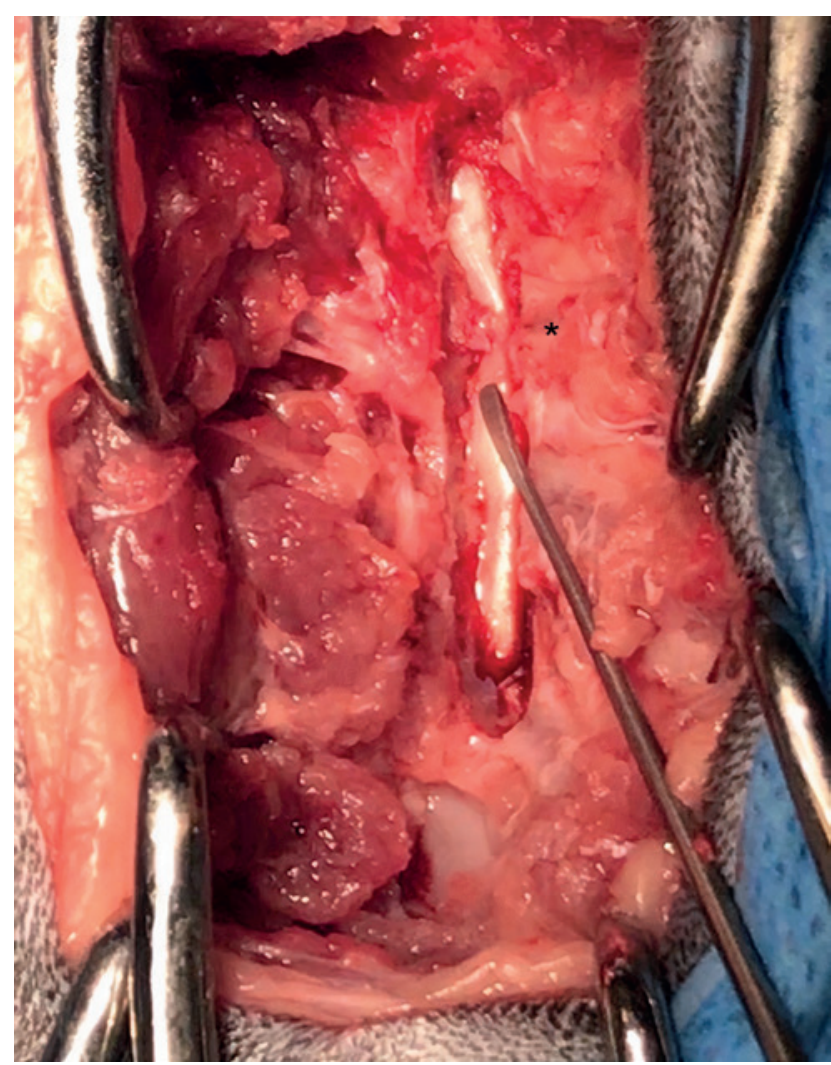

Figure 3. Case 1. Intraoperative picture after T2 to T5 left hemilaminectomy, showing severe dorsolateral deviation of the spinal cord from left to right (instrument point), mainly at the level of T3 (black star).

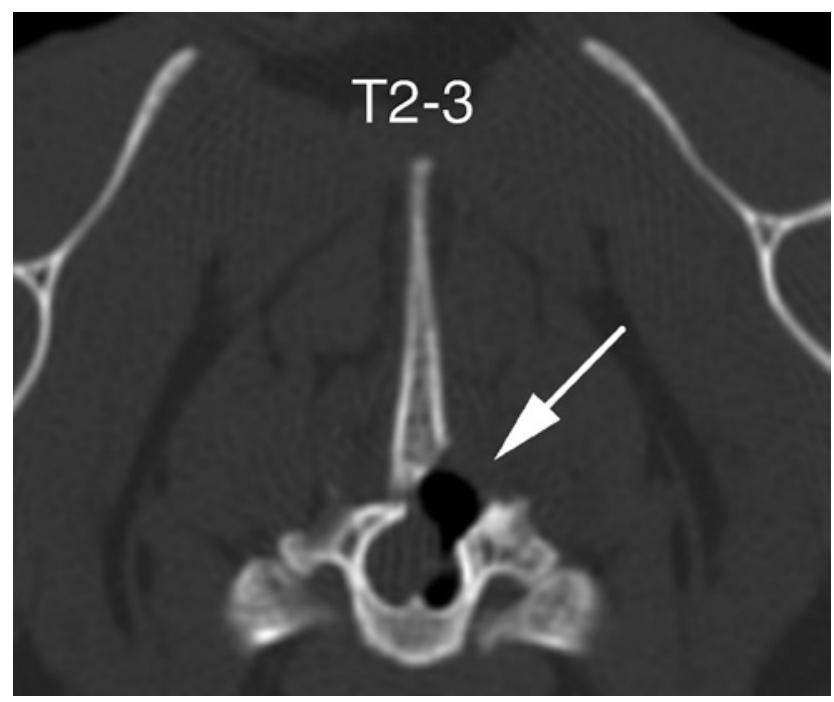

Figure 4. Case 1. Transverse postoperative CT bone algorithm acquisition at the level of T2-T3, showing satisfactory decompression of the spinal cord after left side hemilaminectomy (white arrow).

\section{Case 2}

An eleven-year-old, female, neutered British Shorthair cat was presented with a four-month history of progressive weakness, ataxia and muscle atrophy in both pelvic limbs. According to the owner, the condition appeared non-painful. During these four months, a two-week treatment with $1 \mathrm{mg} / \mathrm{kg}$ q24h predniso- lone (Prednicortone $\AA$; Kela Veterinaria NV, Belgium) followed by a twelve-day treatment with robenacoxib (Onsior $®$; Novartis Pharma NV, Belgium) $2 \mathrm{mg} / \mathrm{kg}$ q24h did not cause any improvement of the clinical signs. Prednisolone was again prescribed at the same dose for a longer period and some improvement was seen. However, since the clinical signs did not entirely resolve, the cat was referred for further investigations. General physical examination, complete blood cell count and biochemistry profile were all unremarkable. On neurological examination, the cat was ambulatory paraparetic with marked proprioceptive ataxia and delayed postural reactions (proprioception and hopping) in both pelvic limbs. Moderate generalized muscle atrophy was present at both pelvic limbs. Pain could be elicited on palpation of the thoracolumbar vertebral column. Segmental spinal reflexes were normal. These findings were consistent with T3-L3 myelopathy.

CT of the thoracolumbar vertebral column was performed using the same protocol and technique as previously described. On the native sequences, some mild new bone formation was seen ventrally at the vertebral bodies of T11, T12, T13 and L3. At the level of T11-T12 and T12-T13, a mild dorsal spinal cord compression was seen, mainly due to bilateral APH (Figure 5). Based on the CT images, mild to moderate intervertebral disc extrusion at the level of T11-T12 and mild protrusion at the level of T12-T13 were suspected. Low field MRI using a permanent $0.2 \mathrm{~T}$ magnet (Airis Mate, Hitachi Ltd) was performed and revealed decreased T2W signal intensity in all thoracic and lumbar intervertebral discs, but most pronounced at the level of T11-T12 (Figure 6A). At this level, a dorsal and ventral compression of the spinal cord was detected with adjacent intramedullary T2W and STIR hyperintensity and T1W isointensity of the spinal cord extending from mid T10 until the caudal aspect of T13. After intravenous administration of $0.1 \mathrm{mg} / \mathrm{kg}$ paramagnetic contrast medium gadoterate meglumine (Dotarem $\AA$; Guerbet, the Netherlands), a mild ventral meningeal hyperintensity was seen at the level of T11-T12. Mild spinal cord compression due to APH at the level of T11-T13, with diffuse right sided intramedullary signal and meningeal enhancement on MRI images were also seen, compatible with spinal cord edema (Figure 6B).

Lumbar cerebrospinal fluid (CSF) analysis was performed, including total nucleated cell count and total protein concentration, which were unremarkable. A presumptive diagnosis of mild disc extrusion at T11-T12 and mild protrusion at T12-T13 was made, with mild thoracic vertebral canal stenosis due to APH at the level of T11-T13. The owners opted for conservative treatment and the cat was treated with $1 \mathrm{mg} / \mathrm{kg}$ prednisolone q24hs (Prednicortone $\AA$; Kela Veterinaria NV, Belgium). After one month, the owners were contacted by telephone. Some mild improvement was seen and the cat was still receiving prednisolone 0.5 mg/kg q48hs. 
Figure 5. Case 2. Transverse CT bone algorithm acquisition at the level of T11 to T13, showing mild dorsal spinal cord compression due to hypertrophy of the articular processes (black star).
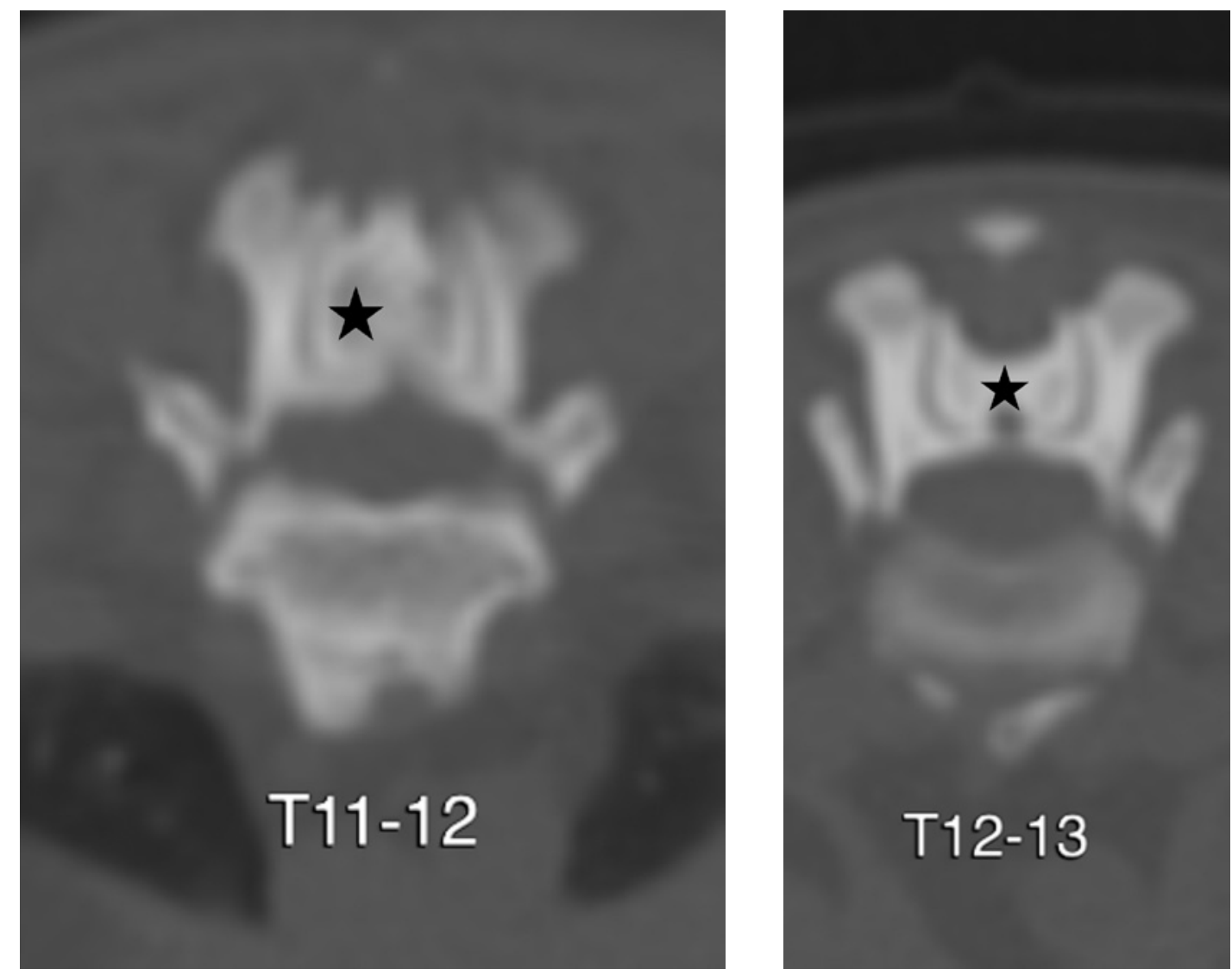

Case 3

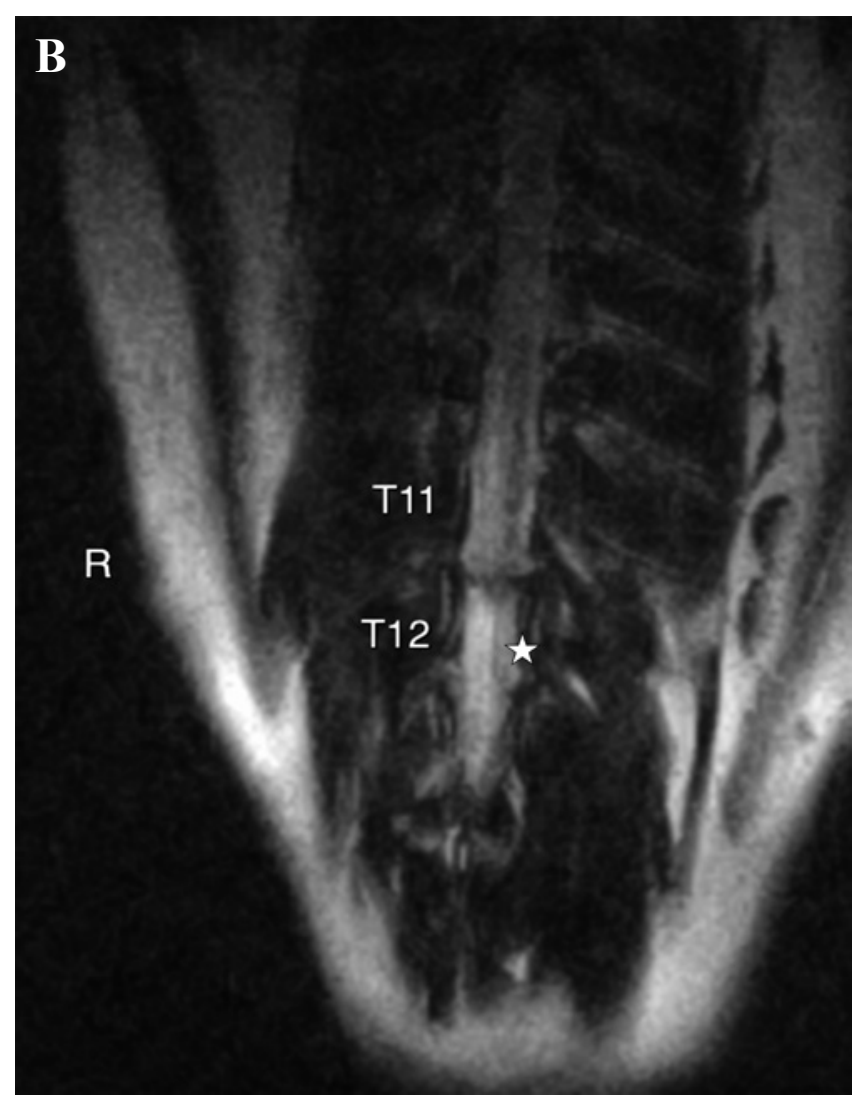

A six-year-old, male, castrated European Shorthair cat was presented for a two-month history of back pain and left pelvic limb lameness. This cat was adopted at a younger age and the right pelvic limb had already been amputated due to an unknown cause. The referring veterinarian prescribed $1 \mathrm{mg} / \mathrm{kg}$ q24h methylprednisolone (Moderin $\AA$; Zoetis BV, Belgium), without clinical resolution and the cat was referred for further investigations. General physical examination

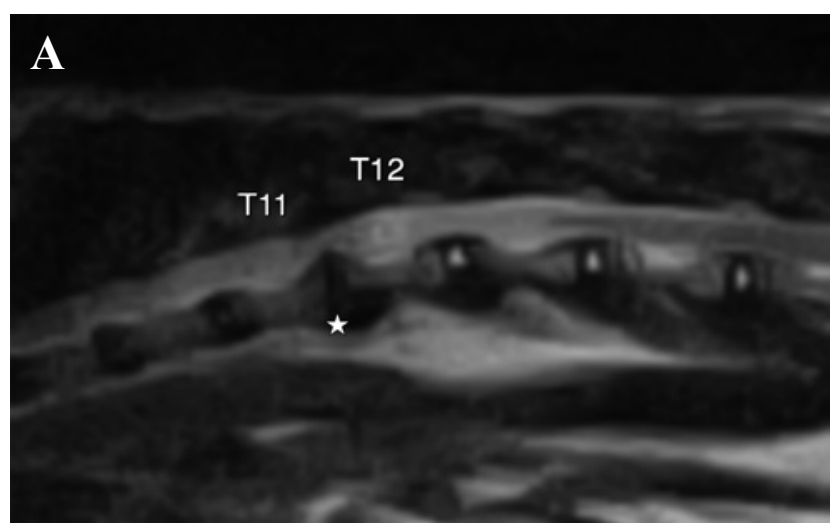

Figure 6. Case 2. A. T2W transversal 0.2T MR image showing dorsal and ventral compression of the spinal cord with decreased signal intensity at the T11-T12 intervertebral disc (white star). B. T2W dorsal 0.2T MR post contrast image showing diffuse right sided intramedullary signal between T10-T13, compatible with spinal cord edema (white star). 
revealed no abnormalities. On neurological examination, the cat looked uncomfortable while walking (kyphotic posture), showing left pelvic limb paresis, because of which it sometimes fell whilst walking. Hyperesthesia was evident on palpation of the thoracolumbar and lumbar vertebral column and the cat appeared uncomfortable on manipulation of the tail. The remainder of the neurological examination was unremarkable. These findings were most likely due to T3-L3 myelopathy. Complete blood cell count and biochemistry profile were unremarkable.

$\mathrm{CT}$ of the vertebral column was performed using the same protocol and technique as previously described in case 1. Bilateral APH at the level of T10T13 was present, causing moderate dorsal compression of the spinal cord. The remaining bony structures were within normal limits. There was also a mild APH of the lumbar vertebrae L1-L5 without significant compression of the spinal cord. Lumbar CSF analysis was unremarkable. The presumptive diagnosis in this case was APH at the level of T11-T13 causing dorsal compression of the spinal cord. Conservative treatment with $10 \mathrm{mg} / \mathrm{kg}$ gabapentine q8h (Neurontin ${ }^{\circledR}$; Pfizer NV, Belgium) was started and one month later, the cat was showing no signs of pain anymore and the paresis had improved but was not totally resolved. After six months, the owner was contacted via telephone for follow-up. The cat was still receiving gabapentine and the clinical signs were stable.

\section{DISCUSSION}

In this case series, the clinical presentation and imaging findings of multiple APH are described in one European and two British Shorthair cats. APH is a rarely reported cause of myelopathy in cats, and so far, only reported as a single site lesion (Bossens et al., 2015; Carletti et al., 2019). In the previously reported cases, the lesions were localized in the thoracic vertebral column. In this case series, APH could be found not only in the thoracic but also in the lumbar vertebral column (cases 1 and 3). All three cats presented a history of chronic progressive myelopathy. Predilection for APH appears to exist in older cats (middle-aged and senior). Similary to previously reported cases (Bossens et al., 2016; Carletti et al., 2019), the three cats of the present report were older than six years at the time of the diagnosis. Imaging findings of APH are compatible with enlargement of the articular processes, with these projecting into the vertebral canal and causing uni- or bilateral extradural compression of the spinal cord. As seen in case 2, a focal area of intramedullary hyperintensity might be present on T2-weighted MRI, compatible with spinal cord edema secondary to the compression. Important differential diagnoses for APH include hamartomas (Taylor-Brown et al., 2018), angiomatosis (Schur et al., 2010; Hans et al., 2018) and neoplastic processes
(Besalti et al., 2016). These differential diagnoses can be differentiated on the basis of histopathological features.

APH leading to vertebral canal stenosis is a wellrecognized condition in dogs (Da Costa, 2010). Often, more than one vertebral site is compromised, with T2- T3 being the most commonly affected site (Johnson et al., 2012). The etiopathogenesis of APH in cats is not fully understood, but it is believed to be similar to dogs, where APH is thought to be due to developmental abnormalities, bone dysplasia or malarticulation (Johnson et al., 2012). Adjacent spinal cord disease was not detected in case 1 and case 3 . However in case 2, spondylosis deformans and intervertebral disc disease (IVDD) were detected at T11-T12 (extrusion) and T12-T13 (protrusion) where APH was also present. In this case, the presence of a chronic intervertebral disc protrusion may have predisposed to instability and subsequent hypertrophic changes of the articular processes at this level (Carletti et al., 2019). The authors believe that the spinal cord compression caused by IVDD in case 2 contributed to the clinical signs, causing a dorsoventral compression at this level and exacerbating the neurological deficits. Based on the imaging findings in cases 1 and 3, APH seemed to be the main cause of the clinical signs whereas in case 2 , APH could just as well have been an incidental finding. It was difficult to advise all three cat owners on expected prognosis, primarily because of the lack of available long-term outcome data for APH in cats, the multifocal aspect of this condition and the possibility of being just an incidental finding, especially in case 2. Short-term clinical improvement has been achieved with conservative treatment in one case (Bossens et al., 2016) and with surgical decompression alone in two cases (Carletti et al., 2019). Both cats, i.e. a nineyear-old, neutered, female British Shorthair cat and a thirteen-year-old, castrated, male domestic Shorthair cat were presented with a history of chronic progressive myelopathy and were treated surgically. Magnetic resonance imaging (MRI) revealed the presence of a bilateral enlargement of the articular processes projecting into the vertebral canal causing bilateral dorsal extradural compression of the spinal cord. In the present report, both cats that were treated medically, showed marked improvement without complete remission of the clinical signs. Gabapentine was only administered in case 3 since pain was more obvious than in case 2 and for this reason, case 2 only received prednisolone. Unfortunately, the cat in the present series that was treated surgically, died a few hours after surgery and necropsy was declined by the owners. Respiratory failure due to spinal cord compression is mainly related to the cervical region. In the cat, the phrenic nerves originate from cervical spinal cord segments C5-C6 (Crouch 1969) and these nerves supply motor and sensory fibers to the diaphragm (Evans and de Lahunta, 2013). This cat developed both inspiratory and expiratory dyspnea several hours after an 
uneventful recovery of anesthesia and was accompanied with bilateral crackles on lung auscultation and loss of serohemorrhagic fluid from the nose. The authors believe that this, in combination with an atypical neurolocalization to cause respiratory failure (T2-T5), increased size of the left atrium on FAST scan of the heart and initial positive response after administration of furosemide, makes cardiogenic pulmonary edema due to congestive heart failure likely. Unfortunately, no necropsy was performed and the exact cause of the respiratory failure could not be determined with certainty. Further limitations of this retrospective study were the small number of cases, the possibility of this condition being an incidental finding (mainly in case 2) and the lack of MRI and CSF analysis in two cats (case 1 and 3 ) to exclude other diseases, which might not have been visible on CT.

To the authors' knowledge, the present report represents the first detailed description of CT and/or MRI findings for multiple articular processes hypertrophy in three cats and its neurological signs. APH may not be apparent on survey radiographs, and CT and/or MRI should be recommended to obtain an imaging diagnosis for cats with thoracolumbar myelopathy.

\section{CONCLUSION}

In middle-aged and senior cats presenting with back pain, paraparesis and proprioceptive ataxia, the list of differential diagnoses should include benign but compressive diseases such as APH. Concomitant conditions might be seen on CT and/or MRI and for this reason, the presence of APH should be interpreted with caution when deciding for the best treatment approach in each single case, since this may just be an incidental finding. Surgical treatment may be the key for a good outcome, but since medical treatment might offer fair improvement, the risks of a surgical intervention should be well considered.

\section{REFERENCES}

Adams R.J., Garosi L., Matiasek K., Lowrie M. (2015). Acquired cervical spinal arachnoid diverticulum in a cat. Journal of Small Animal Practice 56, 285-288.

Antila J.M., Jeserevics J., Rakauskas M., Anttila M., Cizinauskas S. (2013). Spinal dural ossification causing neurological signs in a cat. Acta Veterinaria Scandinavica 55(47), 1-6.

Besalti O., Caliskan M., Can P., Vural S.A., Algin O., Ahlat O. (2016). Imaging and surgical outcomes of spinal tumors in 18 dogs and one cat. Journal of Veterinary Science 17(2), 225-234.
Bossens K., Bhatti S., Van Soens I., Gielen I., Van Ham L. (2016). Diffuse idiopathic skeletal hyperostosis of the spine in a nine-year-old cat. Journal of Small Animal Practice 57, 33-35.

Carletti B.C., Espadas I., Sanchez-Masian D. (2019). Thoracic vertebral canal stenosis due to articular process hypertrophy in two cats treated by hemilaminectomy with partial osteotomy of the spinous process. Journal of $\mathrm{Fe}$ line Medicine and Surgery Open Reports 5 (2), 1-5.

Crawford A.H., Cappello R., Alexander A., De Decker S. (2018). Ventral slot surgery to manage cervical intervertebral disc disease in three cats. Veterinary and Comparative Orthopaedics and Traumatology 31, 71-76.

Crouch J.E. (1969). Text-Atlas of Cat Anatomy. Lea and Feiberger: Philadelphia, p. 231.

Da Costa R.C. (2010). Cervical spondylomyalopathy (wobbler syndrome) in dogs. Vet Clin North America Small Animal Practice 40, 881-913.

De Decker S., Warner A.S., Volk H.A. (2017). Prevalence and breed predisposition for thoracolumbar intervertebral disc disease in cats. Journal of Feline Medical Surgery 19 (4), 419-423.

Evans H.E., de Lahunta A. (2013). The spinal nerves. In: Evans H.E. and de Lahunta A. (editors). Miller's Anatomy of the Dog. Fourth edition, Elsevier Saunders, St. Louis, p. 611-657.

Hans E.C., Dudley R.M., Watson A.T., Chalkley M., Foss K.D., Bancroft A., Prescott D.M. (2018). Long-term outcome following surgical and radiation treatment of vertebral angiomatosis in a cat. Journal of the American Veterinary Medical Association 253(12), 1604-1609.

Havlicek M., Mathis K.R., Beck J.A., Allan G.S. (2009). Surgical management of vertebral malformation in a Manx cat. Journal of Feline Medicine and Surgery 11, 514-517.

Johnson P., de Risio L., Sparkes A., McConnell F., Holloway A. (2012). Clinical, morphologic, and morphometric features of cranial thoracic spinal stenosis in large and giant breed dogs. Veterinary Radiology \& Ultrasound 53, 524-534.

Ricci E., Cherubini G.B., Jakovljevic S., Aprea F., Cantile C. (2011). MRI findings, surgical treatment and followup of a myelomeningocele with tethered spinal cord syndrome in a cat. Journal of Feline Medicine and Surgery 13, 467-472.

Schur D., Rademacher N., Vasanjee S., McLaughlin L., Gaschen L. (2010). Spinal cord compression in a cat due to vertebral angiomatosis. Journal of Feline Medicine and Surgery 12, 179-182.

Taylor-Brown F.E., Lamb C.R., Martineau H., Muir C., Beltran E. (2018). Imaging diagnosis-imaging and histopathologic characteristics of a vertebral hamartoma in a cat. Veterinary Radiology \& Ultrasound 59(2), 12-16.

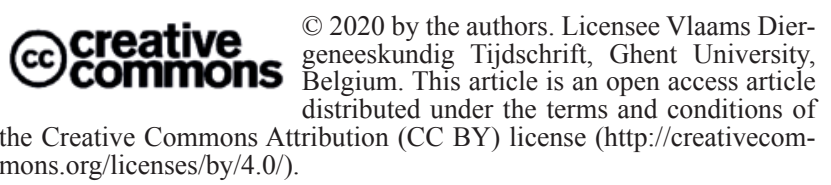

